\title{
Trabalho em equipe interdisciplinar de saúde como um espaço de reconhecimento: contribuições da teoria de Axel Honneth
}

\section{| ${ }^{1}$ Lilian Miranda, ${ }^{2}$ Francisco Javier Uribe Rivera, ${ }^{2}$ Elizabeth Artmann I}

Resumo: O presente estudo teórico tem como objetivo relacionar uma discussão sobre o trabalho em equipe interdisciplinar nos serviços públicos de saúde com os principais conceitos do filósofo contemporâneo Axel Honneth, dentre eles aquele que denominou Luta por Reconhecimento. Para tanto, partimos da revisão da noção de sujeito na teoria honnethiana, sobretudo a partir do diálogo que faz com a psicanálise de Donald Winnicott. Destacamos que se trata de um sujeito eminentemente social, cuja constituição depende do reconhecimento do outro em relação a sua alteridade e da legitimação do seu pertencimento a um grupo social. Mostramos que esse reconhecimento se dá através de um processo de luta, essencial para o desenvolvimento da capacidade de amar e se relacionar com o outro. Em seguida, defendemos que o trabalho em equipes interdisciplinares pode ser um espaço para o reconhecimento dos profissionais, tal como discutido por Honneth. Consequentemente, as equipes podem facilitar o desenvolvimento de trabalhos criativos e inovações na organização da assistência oferecida aos pacientes.

> Palavras-chave: equipe de assistência ao paciente; relações profissional-paciente; interdisciplinaridade, intersubjetividade; Axel Honneth.

\author{
1 Doutora em Saúde Coletiva \\ pela Faculdade de Ciências \\ Médicas da Unicamp e pós- \\ doutora pela Ensp/Fiocruz; \\ professora adjunta do Curso \\ de Psicologia da Universidade \\ Federal Rural do Rio de Janeiro \\ (UFRRJ). Endereço eletrônico: \\ limiranda78@hotmail.com \\ 2 Doutor em Saúde Pública \\ pela Ensp/Fiocruz; pesquisador \\ titular da Fiocruz. Endereço \\ eletrônico: uribe@ensp. \\ fiocruz.br \\ ${ }^{3}$ Doutora em Saúde Coletiva \\ pela Unicamp; pesquisadora \\ titular da Ensp/Fiocruz. \\ Endereço eletrônico: artmann@ \\ ensp.fiocruz.br
}

Recebido em: 10/11/2011 Aprovado em: 28/10/2012. 
Concebida como um dos princípios doutrinários do Sistema Único de Saúde brasileiro (SUS), a integralidade impõe o desafio da implementação de uma forma de trabalho que responda de maneira eficaz às diferentes e emaranhadas dimensões que compõem o processo saúde-doença. Sua sustentação requer um aparato epistemológico que viabilize a interdisciplinaridade, modo de relação entre disciplinas capaz abordar a complexidade do objeto da área de saúde, sobretudo na esfera da Saúde Coletiva (ARTMANN, 2001).

A partir de uma sistematização do pensamento habermasiano, Artmann (2001) destaca o papel fundamental da linguagem na articulação da ação e das diferentes formas de saber. Todas as formas de ação, instrumental ou estratégica, normativa e dramatúrgica, remetem à estrutura básica comum do agir comunicativo, o levantamento de pretensões de validade inerentes aos atos de fala ou unidades pragmáticas da linguagem que os interlocutores intercambiam. Essas pretensões, que se referem a diferentes aspectos ou mundos (objetivo, normativo e subjetivo), configuram pretensōes de verdade, de correção e de autenticidade, sendo naturalmente (ou de forma implícita) compartilhadas no mundo da vida cotidiana das pessoas. Quando contestadas, as pretensões são tematizadas através de argumentos e razões na esfera do discurso argumentativo. Diferentes pretensōes correspondem a discursos diferenciados, como o teórico e o prático. No entanto, dada uma base comum de linguagem, haveria a possibilidade de um trânsito ou passagem regulada do teórico ao prático e vice-versa.

A dialética entre discurso e ação comunicativa inclui determinadas suposições ou critérios reguladores da situação de fala, de caráter ideal, que explicam a possibilidade do entendimento em geral e particularmente do entendimento entre perspectivas de saber ou domínios linguísticos diferenciados. Assim, o projeto interdisciplinar habermasiano está associado à ideia do agir comunicativo como forma de integração da ação em geral e do saber (HABERMAS, 1997).

No cenário das diferentes organizações e serviços de saúde, as equipes profissionais, chamadas em algumas situaçôes de equipes interdisciplinares, representam o lócus privilegiado para a viabilização da interdisciplinaridade. Segundo Peduzzi $(2001 ; 2007)$, elas são concebidas como espaços de articulação entre saberes e ações de distintos profissionais, bem como de divisão do trabalho. Numa leitura habermasiana, a autora analisa as equipes com base na Teoria 
do Agir Comunicativo. Nesse quadro interpretativo, que pressupõe a relação recíproca entre trabalho e interação, temos: (a) da perspectiva do trabalho, o destaque para o âmbito da atividade ou intervenção técnica e (b) da perspectiva da interação, o destaque para a intersubjetividade, que pode ocorrer nos termos do agir comunicativo, tal como analisado por Habermas. Entende-se que é por meio dessa prática comunicativa, caracterizada pela busca de consensos, que os profissionais podem arguir mutuamente o trabalho cotidiano executado e construir um projeto comum pertinente às necessidades de saúde dos usuários, além de reiterar o projeto técnico já dado, no que se fizer necessário.

Peduzzi (2001) reconhece duas tipologias de equipes que coexistem nos serviços de saúde: "equipe de integração" e "equipe de agrupamento". No primeiro modelo, os profissionais buscam a articulação das ações e a interação comunicativa, o que corresponde ao reconhecimento e evidenciação das conexões existentes entre as intervenções técnicas dos membros da equipe, e ao estabelecimento de pontes e ligações entre elas, tendo como condição uma práxis comunicativa que se expressa como o compartilhamento das pretensōes de validade dos proferimentos dos interlocutores. Já a segunda tipologia expressa uma conformação de equipe em que há justaposição de ações e agrupamentos de profissionais, com restrito compartilhamento e pouca comunicação efetiva entre eles. A autora ressalta que em ambas as tipologias estão presentes as diferenças técnicas e as desigualdades de valor atribuídas ao trabalho, bem como as tensōes acerca das concepções e exercícios de autonomia técnica. Destaca, ainda, que na modalidade de integração as diferenças técnicas das distintas especialidades devem ser mantidas, mas subordinadas a um conjunto de valores que expressam o horizonte normativo comum entre os integrantes da equipe. Na equipe de integração, por fim, os trabalhadores são concebidos como interlocutores, e não como objetos de trabalho, tendo o direito ao reconhecimento mútuo e à expressão, sem coação interna ou externa (o que representa uma aproximação a uma situação ideal de fala).

Peduzzi $(2001 ; 2007)$ observa também que, atualmente, entre os valores compartilhados na cultura institucional dos serviços de saúde, prevalecem a fragmentação, as relações hierárquicas de trabalho, o trabalho individualizado por profissional e a resistência de uma racionalidade técnico-científica, além de desigualdades entre as especialidades e a valorização social que lhes é atribuída. 
Rivera (2003) aponta a existência de uma cultura contraditória em transição no contexto hospitalar. Nela, verificam-se atomização profissional, relaçooes hierárquicas em disputa e falta de articulação entre as especialidades, todas convivendo com práticas que envolvem um enfoque de rede, trabalho em equipe e questionamento da fragmentação entre setores e serviços. Assim, observa-se no setor saúde a coexistência de duas tendências contraditórias: fragmentação e segmentação do saber, produtoras de explicações cada vez mais parciais da realidade, convivendo com a construção de um diálogo interdisciplinar para o enfrentamento dos problemas concretos da sociedade.

Essa discussão nos indica que, tão complexas quanto o objeto da área de saúde, são as relações entre seus atores. Por isso, na esteira dessas ideias, propomonos a desenvolver um estudo teórico, cujo objetivo é apresentar e discutir uma perspectiva de análise para o trabalho interdisciplinar em equipes, de modo a contribuir com o enfrentamento das dificuldades e desafios apontados.

Reconhecemos a complexidade desse enfrentamento. Por isso, deter-nos-emos em apenas uma das diversas questões que o envolvem: a necessidade de que as equipes se estruturem como espaço de reconhecimento entre os profissionais e, consequentemente, de desenvolvimento da criatividade e das habilidades de trabalho. Destacaremos, ainda, que a vivência e a expressão de conflitos e disputas de variadas ordens são intrínsecas a essa necessidade de reconhecimento.

Para tratar desse tema, apoiar-nos-emos na teorização que o filósofo contemporâneo Alex Honneth faz do processo por ele denominado "luta por reconhecimento". Partimos da concepção desenvolvida pelo autor, em diálogo com o psicanalista Donald Winnicott, acerca do processo de formação da identidade subjetiva e, em seguida, apresentamos os principais aspectos da luta que o sujeito empreende para ser reconhecido em sua singularidade. $\mathrm{O}$ artigo está divido em duas partes: na primeira, apresentamos os aspectos da teoria de Honneth que nos auxiliam na discussão acerca do trabalho em equipe interdisciplinar; na segunda, apoiamo-nos nessa apresentação para discutir algumas potencialidades e problemas dessa abordagem para a compreensão do trabalho em saúde.

\section{Breve contextualização dos estudos de Axel Honneth}

Axel Honneth possui escritos na área de filosofia social, política e moral, constituindo um programa de pesquisa voltado para a compreensão das relações 
de poder, reconhecimento e respeito nas sociedades capitalistas modernas (WERLE, 2008). Sua obra se inscreve na chamada Teoria Crítica, campo que procura compreender a sociedade à luz da emancipação ao mesmo tempo possível e bloqueada pela lógica própria da organização social vigente (NOBRE, 2003).

No bojo da Teoria Crítica, o pensamento de Honneth pode ser inicialmente situado a partir da obra de Habermas, marcada pela teorização de um mundo da vida permeado por atos de fala que visam ao entendimento. Para Habermas, a forma social própria da modernidade é aquela em que a orientação da ação para o entendimento se encontra no próprio processo de reprodução cultural, que permite a continuidade da interpretação do mundo, de tal modo que a racionalidade comunicativa está inscrita na realidade das relaçóes sociais contemporâneas (NOBRE, 2003). Honneth defende que a intersubjetividade é condição para a constituição e a emancipação humanas, o que pode ser lido como uma continuidade da teoria habermasiana da comunicação (CAMARGO, 2006).

$\mathrm{Na}$ fase madura de sua obra, Honneth se mostrou interessado em reconstruir a Teoria Crítica a partir do conceito habermasiano de interação comunicativa, concentrando o foco de atenção nas causas sociais responsáveis pela violação sistemática das condições de reconhecimento dos grupos e dos sujeitos. Estes estão em busca não apenas do consenso, mas, sobretudo, do reconhecimento (HONNETH, 2009).

Honneth prioriza o estudo das lutas sociais que se originam em experiências de desrespeito social e ataques à identidade pessoal ou coletiva, diferenciando-se de autores que centralizam a discussão na luta pela autoconservação ou pelo poder (NOBRE, 2003). Para tanto, baseando-se em Hegel, ele não pressupõe um sujeito livre com uma realidade abstrata, mas se preocupa com o processo de formação (pré-condiçôes emocionais) do sujeito autônomo, negando a ideia de indivíduo criador de si mesmo (MATTOS, 2004). Tal formação se dá, eminentemente, no campo da intersubjetividade e através de processos que também envolvem uma espécie de luta pela constituição da própria subjetividade.

\section{O processo de constituição subjetiva na perspectiva de Axel Honneth}

Para abordar o processo de formação do sujeito autônomo, Honneth se apoia na teoria do amadurecimento pessoal, elaborada por Donald Winnicott. Segundo 
esse autor, todo ser humano nasce com uma tendência inata ao desenvolvimento, que, para estabelecer-se, depende fundamentalmente do suporte de um ambiente provedor da satisfação de suas necessidades básicas. No início da vida, mãe e filho encontram-se num estado de fusão, de tal modo que a primeira consegue perceber as necessidades do segundo e satisfazê-las a contento.

Tal estado vai se dissolvendo na medida em que o bebê consegue, gradativamente, diferenciar-se do ambiente e conquistar patamares maiores de desenvolvimento intelectual, podendo suportar períodos, cada vez mais longos, de ausência da mãe. A criança inicia um período de desilusão, pois passa a se dar conta de que há aspectos que fogem de sua área de domínio. Na leitura que faz da obra winnicottiana, Honneth pontua que, ao vivenciar a mãe como algo que está fora do seu controle onipotente, a criança adquire, concomitantemente "[...] uma percepção germinal de sua dependência: ela sai da fase de 'absoluta dependência’ porque a própria dependência da mãe entra em seu campo de visão [...]" (HONNETH, 2009, p.167).

A teoria winnicottiana apresenta dois processos através dos quais a criança consegue lidar com a experiência de desilusão: o "uso do objeto" e a "transicionalidade". O primeiro diz respeito ao momento em que, sendo percebida como externa, a consistência da mãe é testada através da destrutividade do bebê, que passa a atacá-la com seus chutes e mordidas. Ao sobreviver a tais ataques, sem retaliar ou deixar de amar o filho, a mãe lhe indica que está fora do seu controle onipotente, embora continue destinando-lhe amor e cuidado. Essa possibilidade de ser amado, a despeito de sua agressividade, oferece condições para que o bebê confie na existência de um mundo que, embora não seja controlável, pode ser confiável (WINNICOTT, 1990).

Nessa perspectiva:

[...] os atos destrutivos e lesivos não são a expressão de uma elaboração negativa de experiências frustrantes; eles foram os meios construtivos com base nos quais a criança pode chegar a um reconhecimento da mãe [...] como um ser com 'direito próprio' [...], então ele se torna capaz, através da integração de seus impulsos agressivos, de amá-la sem fantasias narcísicas de onipotência. [...] (HONNETH, 2009, p.169).

Através dessas elaborações, Honneth (2009) chega à proposta de que a própria formação subjetiva humana se dá através de um processo intersubjetivo de "luta por reconhecimento", uma vez que por meio de uma luta, caracterizada pela tentativa de destruição da mãe, a criança vivencia o fato de que "[...] depende da 
atenção amorosa de uma pessoa existindo independentemente dela, como um ser com pretensões próprias.” (p. 170). Nesse panorama, também a mãe precisa conquistar a capacidade para reconhecer a independência do filho, pois:

[...] a carga agressiva da situação requer que compreenda as fantasias e desejos destrutivos do filho como algo que vai contra os seus próprios interesses e que, por isso, só compete a ele, como uma pessoa já autônoma. [...] (HONNETH, 2009, p.170).

Trata-se de um processo em que mãe e filho lutam para que sejam reconhecidos como seres diferenciados, embora dependentes do amor recíproco um do outro.

Já em relação ao tema da transicionalidade, Winnicott (1975) destaca que, desde muito cedo, as crianças tendem a desenvolver relações afetivas intensas com objetos, ou uma parte deles, tratados com grande ternura e, ao mesmo tempo, agressividade ou destrutividade. Esses objetos e, mais tarde, o próprio brincar, situam-se num domínio intermediário, no qual coexistem o mundo interno da criança, marcado por suas fantasias e desejos, e o mundo empírico, das circunstâncias mais objetivas. Esse domínio intermediário é denominado "espaço transicional” e tem a função de representar formações substitutivas para a mãe, com quem o bebê não pode mais ter uma relação de indiferenciação. As experiências nesse espaço permitem que a criança experimente continuamente os processos de fusão e separação, o que possibilita que os elabore paulatinamente.

Pretendemos mostrar que o trabalho em equipe nos serviços públicos de saúde pode ser um espaço para o reconhecimento intersubjetivo e, consequentemente, para a ação criativa e colaborativa. Para tanto, considerando o modo como Honneth compreende a formação da identidade subjetiva, passaremos a apresentar suas consideraçôes acerca do reconhecimento no campo intersubjetivo, pessoal e social, bem como as lutas para conquistá-lo.

\section{Formas de reconhecimento}

Honneth (2009) traz algumas contribuições no sentido de explorar melhor o conceito de mundo interno, já caracterizado por Habermas (1987) a partir da psicologia social de George Mead, como importante aspecto da racionalidade, dentro da perspectiva de um mundo descentralizado ou plural. Para Honneth (2009), todo sujeito precisa do reconhecimento de si no seu processo de desenvolvimento subjetivo, de modo que possa vivenciar e satisfazer suas necessidades. 
Baseando-se na filosofia de Hegel e nos formulações de Mead, o autor distingue três esferas de reconhecimento, comuns a todos os homens. A primeira delas diz respeito às relações afetivas que convergem para o reconhecimento do indivíduo como um ser carente concreto. Ela envolve a família e o sentimento do amor, o qual concederia aos indivíduos a experiência primária de serem reconhecidos em sua individualidade, bem como a conquista da autoconfiança individual. A segunda esfera está no reconhecimento cognitivo-formal do direito, através do qual o indivíduo é reconhecido como pessoa de direito abstrata, tendo legitimada a sua liberdade e autonomia para agir na sociedade civil, o que permite ao indivíduo a conquista de seu autorrespeito. A terceira esfera refere-se ao reconhecimento do Estado e à solidariedade, conferindo ao indivíduo a condição de sujeito socializado em sua unicidade. Através dela, o sujeito conquista sua autoestima, pois se trata da possibilidade de os indivíduos considerarem-se

[...] reciprocamente à luz de valores que fazem as capacidades e as propriedades do respectivo outro aparecerem como significativas para a práxis comum. Relaçōes como essa [...] não despertam somente a tolerância para com a particularidade individual da outra pessoa, mas também o interesse afetivo por essa particularidade [...]. (HONNETH, 2009, p.210-211).

As esferas de reconhecimento são, portanto, o Amor, a Ordem Social e a Solidariedade. A dignidade e a integridade física do ser humano dependem do reconhecimento nessas três esferas, sendo que as lutas e conflitos sociais seriam consequência de ameaças à integridade física da pessoa, bem como de desrespeito pessoal e social.

A partir de Mead, Honneth (2009) aprofunda sua discussão sobre o conflito inerente ao processo de reconhecimento, lembrando que é a interação social que nos permite adquirir consciência de nós mesmos: ao perceber-se sob a perspectiva de uma segunda pessoa, o indivíduo pode formar uma imagem cognitiva de si. Junto dessa imagem, formada a partir da interação com o mundo social, coexiste outra dimensão do eu, caracterizada pela espontaneidade e pela criatividade que expressa a singularidade ou a diferença do sujeito em relação à sociedade, nem sempre compatível com as normas intersubjetivamente construídas na relação com o outro. Assim, embora nos formemos a partir da interação social, admitese a existência de elementos eruptivos que nos distinguem das normas que construímos socialmente (embora participemos dessa construção) e que também lutam por seu reconhecimento. 
Nessa perspectiva, a evolução da humanidade se deve às lutas empreendidas pelo homem para conferir expressão social à sua criatividade e impulsividade, o que ampliou as relações de reconhecimento. Porém, concordando com os escritos de Mead, Honneth (2009) pondera que a luta por reconhecimento só pode ocorrer quando o sujeito já se sabe reconhecido, de uma maneira elementar, como membro de uma coletividade.

Honneth (2007) tratou dos temas sociais de forma ampla, destacando que a luta por reconhecimento, identificada nas tentativas de reassegurar uma identidade cultural/social, está emaranhada em objetivos materiais das lutas de classes. A fundação das comunas no início do século XX, as lutas afroamericanas resultantes da escravidão e a resistência anticolonial são exemplos dessas lutas em que os âmbitos social/cultural e material estão conectados. Para o autor, não é possível estabelecer uma hierarquia clara entre esses dois âmbitos. Nesse sentido, discute as relações entre as lutas por redistribuição material e por reconhecimento, defendendo que os conflitos sobre distribuição material são sempre lutas simbólicas pela legitimidade do dispositivo sociocultural que determina o valor das atividades, atributos e contribuições. Portanto, a concessão de direitos sociais e a redistribuição de renda cumprem essa ética democrática de reconhecimento do sujeito enquanto pertencente a uma sociedade de igualdade de direitos.

Buscando discutir essas questôes no campo da Saúde Coletiva, defendemos, a seguir, que as equipes interdisciplinares são arranjos propícios para a luta pelo reconhecimento e, consequentemente, para um trabalho criativo e colaborativo.

\section{Equipes interdisciplinares: espaço para a luta e o reconhecimento}

As equipes interdisciplinares são um espaço dinâmico, constituído por saberes, tecnologias, modos de atuação, discursos, necessidades e tipos de relações que, em contínuo movimento de afetação, integração e desintegração, constituiriam modos de ação pautados em determinada organização coletiva das relações e das práticas. Essa configuração impede que as equipes admitam uma conformação rígida e deslocada das características factuais dos membros que as compõem e do espaço sociopolítico que as compreende e constitui (MIRANDA; ONOCKO CAMPOS, 2010). 
Os estudos de Honneth (2007; 2009) enriquecem a discussão sobre a dinâmica de relações nas equipes, remetendo-nos à análise da dimensão de uma luta que, provavelmente, subjaz a esse processo relacional. Luta essa que, se negligenciada, poderá favorecer o autoritarismo (pois mascara o poder das frações dominantes), prejudicando o reconhecimento das diferenças internas do grupo (FRASER, 2007, p. 117).

Entendemos que os aspectos da teoria de Honneth acima apresentados indicam um caminho para vislumbrarmos na equipe interdisciplinar um campo em que, através dos movimentos de interação, os profissionais buscam reconhecimento de diferentes ordens: capacidade profissional, valoração de classe, habilidade pessoal para o trabalho, estilo de se relacionar e se posicionar ante os problemas, dentre outros. As equipes interdisciplinares são um espaço de embate entre diferenças, de luta entre discursos diversificados.

Para Furtado (2007), a prática da interdisciplinaridade na área de saúde exige o enfrentamento do antagonismo entre duas lógicas: aquela pautada na necessidade de diferenciação e sustentada pela profissão e a pautada na integração, que se apoia no trabalho de colaboração interprofissional. $\mathrm{O}$ autor adverte que "[...] o desafio de promover a colaboração não deve ser levado à frente negando uma especificidade duramente alcançada, mas tentando estabelecer pontes entre posições inicialmente antagônicas” (p. 245). Nessa perspectiva, a implementação de um trabalho interdisciplinar nos serviços do SUS é especialmente complexa, já que se trata de um setor constituído por especialidades regidas por órgãos de regulação legal do exercício profissional, bem como por interesses ligados à reserva de mercado e pela necessidade de enfrentar as vicissitudes do contato com um tipo de objeto de trabalho caracterizado pela dor e pela morte. Consequentemente, as equipes interdisciplinares caracterizam-se por uma racionalidade paradoxal, marcada por movimentos constantes de integração e separação.

\section{O reconhecimento dentro da equipe}

Considerando que a capacidade para colaborar depende da possibilidade de reconhecer o outro em sua alteridade, a leitura de Honneth (2009) nos permite afirmar que as equipes comportam um espaço de luta pelo reconhecimento, pois “[...] o indivíduo só pode se proporcionar um sentimento de garantia a respeito de ser reconhecido por seu parceiro mediante a experiência da reação 
prática com que aquele responde a um desafio deliberado, ou mesmo a uma provocação." (HONNETH, 2009, p.64). Assim, as equipes seriam um espaço onde, para construir pontes que ligam uns aos outros, tal como sugere Furtado (2007), os profissionais poderiam testar suas diferenças, desafiar-se e conhecerse quanto àquilo que pode não lhes agradar. A construção de pontes depende do reconhecimento dos diferentes posicionamentos e da legitimidade destes, de tal modo que os profissionais desejem ou, ao menos, admitam a necessidade de visitarem-se uns aos outros, em suas especificidades discursivas, técnicas, epistemológicas e valorativas.

É preciso admitir, entretanto, que esse processo de embates com o outro e o reconhecimento deste requer, ao menos, a habitação de uma espécie de solo comum, ou a existência de alguns conceitos prévios, a partir dos quais os profissionais se comuniquem. Assim, Peduzzi (2001; 2007) lembra que as diferenças técnicas ou especialidades, bem como as distintas intervençôes, devem ser mantidas numa equipe, mas precisam se subordinar a uma base ética de correção normativa, que pode remontar aos valores constitutivos do SUS: integração, democracia e horizontalização.

Admitimos, contudo, que a experiência constante da luta por reconhecimento pode ser profundamente desestabilizadora para a equipe, chegando a inviabilizar a capacidade de trabalho. Para Onocko-Campos (2005), a gestão do serviço assume a função de lidar com a carga afetiva própria dos embates, colocando-se como um espaço intersubjetivo, capaz de operar coletivamente as questôes da instituição, constituindo-se "[...] como uma instância, com um lugar e um tempo onde se possa experimentar a tomada de decisões coletivas e analisar situações com um grau de implicação maior em relação àquilo que é produzido [...]” (p. 577). Ressaltamos que tal instância teria a função de possibilitar a circulação da fala e da autorreflexão, aumentando não somente o grau de análise das práticas, mas também a compreensão e o manejo dos estados pulsionais inconscientes, matéria-prima das lutas pelo reconhecimento.

A partir de uma leitura habermasiana, Artmann e Rivera (2006) também entendem que a gestão pode facilitar a comunicação e o reconhecimento nas relações entre profissionais, na medida em que é uma gestão estratégica, cujas principais funções são: reforço da capacidade explícita de fixação de prioridades de ação e investimentos; avaliação constante do custo-efetividade das aplicações 
de recursos, em detrimento da barganha indiscriminada; visão do ambiente como recurso ou do outro como colaborador; criação de transversalidades de saberes e ações; formalização do planejamento e da avaliação periódicos; criação de lugares de encontro e comunicação entre profissionais; maior relacionamento entre gestores e operadores; ênfase na negociação e fortalecimento do sentido de bem coletivo da atividade.

Arriscando uma analogia com as propostas de Honneth (2009), supomos que no campo das equipes interdisciplinares, a primeira esfera de reconhecimento - o Amor - diria respeito às relações dos profissionais entre si e com os usuários. Isso corresponde ao que Campos (2003) define como vínculo, ou seja, um processo de transferência de afeição. A luta pelo reconhecimento nessas relações seria fonte de autoconfiança não só dos profissionais, como também dos usuários. Essa esfera seria composta por dimensões diversificadas, tais como o reconhecimento de certo "saber-fazer" dos profissionais, bem como das qualidades, exigências e necessidades dos usuários. Assim, para além das capacidades técnicas previamente esperadas para cada especialidade ou dos sintomas próprios de cada patologia, esperar-se-ia o reconhecimento de traços singulares, ainda que coletivamente construídos, tanto de trabalhadores da saúde como de pacientes.

A respeito dessa esfera de reconhecimento, vale ressaltar que, para Saavedra (2007), o nível de reconhecimento do Amor é fundamental não apenas para o desenvolvimento do autoconfiança, mas também para a conquista da autonomia necessária para a participação na vida pública. Trata-se da base para as relações sociais entre adultos, e também do núcleo fundamental de toda moralidade.

A segunda esfera de reconhecimento - Ordem Social - se referiria à relação da equipe com o serviço, e de ambos com os usuários, o que inclui a missão institucional, as normas, regras e padronizaçóes pactuadas, o regime de trabalho e remuneração estabelecidos, as políticas vigentes de recursos humanos e educação em serviço, dentre outros aspectos. É a esfera dos direitos, que consagra a liberdade individual, a capacidade de participar em condição de igualdade nos processos de decisão e formação da vontade, e também o direito a condições mínimas de sobrevivência material e de trabalho. Esse reconhecimento supõe o desenvolvimento de colegiados de gestão, de processos participativos de decisão, os quais, junto à reivindicação de condições de trabalho, reforçam a perspectiva da humanização em saúde. Esses direitos incluem os interesses do usuário e a 
perspectiva do "direito à saúde", que está na base do acolhimento. Note-se que nessa esfera a regulação do trabalho e dos direitos do trabalhador deve permiti-lo ter reconhecida a autonomia necessária ao exercício do trabalho (o reconhecimento é intrínseco à regulação), o que proporcionaria à equipe o autorrespeito.

Finalmente, a esfera da Solidariedade corresponderia às relações da equipe e do serviço com a comunidade de valores e o Estado. Espera-se que os últimos reconheçam a importância e as peculiaridades do trabalho desenvolvido pelos vários membros do serviço, atribuindo-lhes um valor e um lugar social, o que contribuiria para a conquista de autoestima da equipe interdisciplinar. Essa esfera implica o reconhecimento da contribuição singular de cada membro da equipe, bem como da importância para o trabalho coletivo do projeto de autorrealização de cada categoria profissional.

Honneth (2009) afirma que a sociedade é tributária de variadas lutas pelo reconhecimento, indicando que este não está naturalmente dado, mas requer dos homens um contínuo esforço de conquista. Consequentemente, faz-se necessário ponderarmos que as equipes interdisciplinares devem estar em constantes lutas por patamares de reconhecimento cada vez maiores e mais complexos.

Podemos encontrar um possível exemplo dessa luta ao nos determos, ainda que rapidamente, na temática do acolhimento e da humanização do atendimento em saúde. Teixeira (2003) entende que o acolhimento envolve uma escuta atenta às demandas do paciente a partir do reconhecimento do seu direito moral e de sua condição de legítimo outro. Além disso, envolve as possibilidades do trabalhador em perceber-se sempre insuficiente (seu saber é mais um dentro de um conjunto de outros conhecimentos necessários a cada caso) e sua capacidade para estabelecer um diálogo que lhe permita identificar e priorizar as necessidades de intervenção, sejam elas tecnológicas, subjetivas ou sociais. Portanto, num atendimento, o paciente teria que, de alguma forma, lutar para ter reconhecidas suas necessidades, direitos e potencialidades (com as quais pode se cuidar).

Ressalta-se que essa concepção de acolhimento se baseia num modelo de comunicação habermasiano de entendimento, em que se leva em consideração uma interação que vai além do binômio emissor-receptor, requerendo ajustes das falas à diversidade cultural e às especificidades subjetivas do usuário e do profissional (ARTMANN; RIVERA, 2006). Nesse contexto, não só o usuário depende dos cuidados do profissional, mas este também precisa do apoio do 
primeiro para fundar seu diagnóstico, encaminhar sua estratégia terapêutica e, enfim, ter sua capacidade clínica respeitada.

$\mathrm{Na}$ comunicação voltada para o entendimento, a luta pelo reconhecimento é um dos componentes centrais: paciente e profissional precisam fazer-se compreender para que sejam reconhecidos e possam estabelecer uma relação de confiança, que é o sustentáculo de qualquer processo terapêutico. Alguns arranjos institucionais, como a gestão colegiada e a divisão dos serviços de saúde em unidades de produção, compostas por equipes multiprofissionais, criam condições favoráveis a essa forma de comunicação e, consequentemente, à troca de informações e à construção coletiva de projetos terapêuticos.

Vale ressaltar que estes, tal como definem Campos e Dominitti (2007), são um processo de negociação, no interior de uma equipe multiprofissional, que deve compor um projeto de intervenção singular para cada caso ou usuário, na linha de uma valorização particular das características de cada sujeito envolvido na relação clínica e de uma valorização da importância do trabalho coletivo, multi e interdisciplinar. Portanto, a construção do projeto terapêutico requer o reconhecimento do paciente (no seu direito de acesso à saúde, nas suas necessidades e condições) e dos diferentes profissionais, cuja atuação comporá o cuidado. Tal reconhecimento deve implicar uma responsabilidade de cada especialista em relação não apenas a sua prática individual, mas também ao agir coletivo projetado e pactuado.

Destaca-se, ainda, que o acolhimento teria a capacidade de fortalecer a autonomia e a potência do usuário, na medida em que reconhece não apenas suas fragilidades e necessidades de cuidado, mas também sua sabedoria prática e as estratégias que vem utilizando para enfrentar as precárias condições de vida que o envolvem. Ao mesmo tempo, o profissional tem sua condição de "sujeito autônomo" fortalecida, já que é reconhecido como alguém capaz de cuidar do outro.

Entende-se que a relação profissional-paciente é, por si mesma, assimétrica. Existem diferenças nos níveis de saberes (e poderes, consequentemente) do médico e do paciente. Entretanto, a comunicação e o acolhimento tornam-se possíveis quando os profissionais lançam mão da "correção normativa". Esta, segundo a teoria habermasiana, determina um modo de estruturar a relação a partir da aceitação da alteridade, não havendo a pretensão de eliminar as diferenças, mas de estabelecer diálogos sem coação, de modo que os sujeitos tenham plenas 
chances de assumir compromissos e estabelecer demandas. "[...] Trata-se [...] de reconhecer que os atos linguísticos assumidos por alter são corretos (justos) ou apropriados, porque se apoiam num contexto normativo considerado legítimo, no qual se destaca o direito amplo à saúde”. (ARTMANN; RIVERA, 2006, p.218).

Até aqui, o acolhimento referiu-se à interação profissional-usuário. $\mathrm{Na}$ leitura de Teixeira (2003), há elementos que permitem a extensão desse conceito às interações entre serviços e profissionais, a partir da definição, baseada no diagnóstico das necessidades do paciente que é acolhido, de determinadas formas de distribuição deste pelo sistema de serviços. O acolhimento, nesse caso, representa uma rede conversacional que supóe a busca de um determinado nível de coordenação da ação através de processos linguísticos, entendidos como formas comunicativas ou formas que buscam o reconhecimento recíproco.

No Brasil, têm destaque estratégias operacionais favorecedoras do acolhimento, como o "apoio matricial" (CAMPOS; DOMINITTI, 2007) e o "apoio institucional” (VASCONCELOS et al., 2009), reconhecidos como dispositivos que ajudariam a superar o cuidado fragmentado e a lógica da gestão verticalizada, em prol de um cuidado interdisciplinar e de uma gestão mais horizontalizada, problematizadora, dialógica. Essas estratégias envolvem o reconhecimento do outro através da cooperação, que corresponde a ofertas de núcleos especializados dirigidas à atenção básica de saúde - ou ao nível local de saúde - e a um trabalho de mediação institucional (e não de autoridade) realizado por agentes dos sistemas de direção e gestão e orientado ao fortalecimento da autonomia dos núcleos de trabalhadores locais. O acolhimento como forma de reconhecimento intrínseca a uma rede conversacional voltada para coordenação da ação em bases legitimadas ganha, assim, uma extensão que justifica sua compreensão sob a ótica de Honneth. Nessa medida, o acolhimento pode ser visto como vínculo baseado na emoção e afetividade básicas, como direito à saúde ou corpo normativo baseado na justiça e nos direitos civis e humanos, e como reconhecimento - no terceiro estágio aludido - das singularidades de cada agente ou membro de uma equipe multiprofissional e da importância de cada contribuição particular para um projeto coletivo. $\mathrm{Na}$ realidade, nesse terceiro estágio, haveria uma tensão entre os processos de diferenciação das categorias e agentes de uma equipe, que reivindicam um reconhecimento, e a formação de uma memória ou consciência coletiva, correspondente a um corpo valorativo comum, onde cada qual quer 
deixar sua marca no plano simbólico. Uma ideia-força, de caráter ético-moral, que orienta esse corpo é a solidariedade. Ser solidário, aqui, significa reconhecer o outro como legítimo outro na diferença.

Em trabalhos como o de Pereira (2011), essa forma de reconhecimento no interior de determinadas modalidades de equipes multiprofissionais da ESF aparece com várias características: existência de articulação entre as categorias profissionais da equipe, o que implica trocas comunicacionais intensas e uma tentativa de criar uma linguagem ou um projeto comum, apesar das diferenças; concepção do trabalho de cada membro como uma atividade coletiva, que depende dos outros; e existência de uma liderança rotativa, em que cada categoria profissional exerce uma determinada liderança, incluindo a do agente comunitário junto à comunidade, também fruto dos vínculos e de uma experiência comum de lutas pelo reconhecimento de suas pretensões de identidade. Nesse último caso, é importante chamar a atenção para os vínculos que o agente estabelece com outras categorias profissionais, como a dos enfermeiros. Numa modalidade de equipeinteração, o reconhecimento implica o exercício da solidariedade, que se evidencia na legitimação da importância de cada categoria profissional em particular, especialmente daquelas tradicionalmente identificadas como possuidoras de um saber periférico, diminuído, e com uma posição de poder restrita, como pode ocorrer com os agentes comunitários. No estudo de Pereira (2011), estes, em determinadas situaçôes, mostraram a capacidade de lutar pelo reconhecimento de sua liderança real, conquistada e não proveniente de cargos formais. A aceitação da legitimidade da diferença dentro do pressuposto de uma forte integração valorativa, que se traduz por uma noção do coletivo, é um achado na análise de experiências já estudadas (PEDUZZI, 2001; 2007; PEREIRA, 2011).

\section{A conquista do reconhecimento e a capacidade para o trabalho criativo}

Um aspecto que pode contribuir para a compreensão da conformação de possibilidades de reconhecimento nas equipes interdisciplinares é a discussão acerca dos espaços transicionais e do desenvolvimento de trabalhos criativos. Conforme vimos no início deste texto, segundo a concepção winnicottiana, esses espaços são zonas intermediárias, onde convivem aspectos dos mundos interno e externo dos sujeitos. Nessas zonas, são construídas “[...] pontes simbólicas 
sobre o abismo dolorosamente vivenciado das realidades interna e externa [...]" (HONNETH, 2009, p.171), permitindo que elas se comuniquem, se interrelacionem. Consequentemente, tais pontes são a matéria-prima para as ações criativas e colaborativas, propiciando aos sujeitos condiçōes para desenvolver um relacionamento espontâneo com suas potencialidades e, ao mesmo tempo, ajudando-lhes a suportar as desilusões próprias do contato com o outro.

Sendo o espaço transicional o lugar em que o sujeito pode estabelecer um relacionamento espontâneo consigo mesmo, arriscamos supor que também é nele que são empreendidas as lutas pela ampliação do espaço de reconhecimento da parte do eu caracterizada pela espontaneidade, criatividade e impulsividade, tal como Honneth discute através do diálogo com George Mead. No contexto das equipes interdisciplinares, essa luta se trava de forma mais complexa, na medida em que os profissionais precisam conquistar a aceitação de suas criações, elaborações, insights, intuições, percepções em meio a vários crivos, provenientes da autoavaliação que fazem de si mesmos, das instâncias reguladoras de suas categorias profissionais, do serviço e do sistema, das concepções e valores dos colegas, da utilidade e da eficácia daquilo que propõem.

Essa liberação progressiva da espontaneidade e criatividade pode ser o motor da evolução da instituição, tal como Honneth (2009) defende em relação à sociedade. Ressaltamos, porém, que ela se dá num processo de luta, em que há que se negociar com as diferentes instâncias reguladoras (pactos coletivos, normas éticas, dentre outras), de modo que a criação é sempre influenciada pela interação social. Esse processo nos indica que as equipes, quando não reprimem os espaços de embate e conflito, propiciam uma constante formação subjetiva dos trabalhadores.

Para exemplificar o que viemos teorizando, sugerimos que uma das formas de experimentar o espaço transicional no contexto do trabalho em equipe são as atividades de discussão de caso, ou construção do caso clínico. Nestas, a partir do conhecimento e da experiência próprios a seus núcleos disciplinares, os diversos profissionais partilham o conhecimento que possuem sobre o caso e, ao mesmo tempo, analisam aquilo que puderam apreender das diferentes relações que cada um teve com os usuários em questão. Note-se que, nesse momento, a equipe habita um espaço paradoxal em que não está atendendo diretamente aos pacientes, mas, concomitantemente, está em contato com conhecimentos objetivos e impressões 
subjetivas que advêm das relações previamente estabelecidas com eles, dentro de um contexto normativo próprio.

Figueiredo (2004) destaca o caráter coletivo desse procedimento, na medida em que o próprio termo construção nos remete a um esforço para partilhar elementos de cada caso, em um trabalho conjunto. Conjunto porque esses elementos são expressos nas diversas relações que o sujeito do caso estabelece com os diferentes membros da equipe, independentemente de núcleo de saber e do grau hierárquico que possuem. Tomando a Teoria do Agir Comunicativo, ressaltamos também o caráter comunicativo das discussões de caso.

A nosso ver, a discussão sobre o enfrentamento da luta pelo reconhecimento e a configuração de espaços de desenvolvimento de ações criativas e de conquista de graus de autonomia, tal como são caracterizados espaços transicionais, podem se associar à análise do trabalho interativo a partir da Teoria do Agir Comunicativo (ARTMANN, 2001; PEDUZZI, 2001; 2007), constituindo um caminho fecundo para a qualificação dos trabalhos em equipe de saúde.

Assim, esperamos que a discussão, a partir das concepções de Axel Honneth, tenha colaborado para a compreensão das equipes interdisciplinares como um espaço que comporta comunicação, formação de consensos e negociação constantes, sempre permeadas por conflitos e lutas, e cujo objetivo final é a possibilidade de o indivíduo reconhecer a si e ao outro como sujeitos autônomos e dependentes, capazes de cooperar e, também, necessitar. ${ }^{1}$

\section{Referências}

ARTMANN, E. Interdisciplinaridade no enfoque intersubjetivo habermasiano: reflexōes sobre planejamento e AIDS. Ciência \& Saúde Coletiva. Rio de Janeiro, v.6, n.1, p.183-195, 2001.

ARTMANN, E.; RIVERA, F.J.U. Humanização no atendimento em saúde e gestão comunicativa. In: DESLANDES, S.F. (Org.). Humanização nos cuidados em saúde: conceitos, dilemas e práticas. Rio de Janeiro: Abrasco, 2003. p.205-31.

CAmargo, S. Axel Honneth e o legado da Teoria Crítica. Política e trabalho. Revista de Ciências Sociais. Fortaleza, v. 24, n.1, p. 123-38, 2006.

CAMPOS, G.W.de S. Saúde Paideia. São Paulo: Hucitec, 2003.

CAMPOS, G.W.S.; DOMINITTI, A.C.Apoio matricial e equipe de referência: uma metodologia para a gestão do trabalho interdisciplinar em saúde. Cadernos de Saúde Pública. Rio de Janeiro, v.23, n.2, p.399-40, 2007. 
FIGUEIREDO, A.C. A construção do caso clínico: uma contribuição da psicanálise à psicopatologia e à Saúde Mental. Revista Latinoamericana de Psicopatologia Fundamental. São Paulo, v. 7, n.1, p. 75-86, 2004.

FURTADO, J.P. Equipes de referência: arranjo institucional para potencializar a colaboração entre disciplinas e profissões. Interface: Comunic, Saúde, Educ. Botucatu, v. 11, n.22, p. 23955, 2007.

HABERMAS, J. Teoria de la acción comunicativa. Taurus-Biblioteca de Filosofia Contemporânea. Madri-Portugal: Ed. 70, 1987.

HONNETH, A. Reconhecimento ou redistribuição? A mudança de perspectiva na ordem moral da sociedade. In: SOUZA, J.; MATTOS, P. (Org.). Teoria crítica no século XXI. São Paulo: Anablume, 2007, p. 79-94.

. Luta por reconhecimento. A gramática moral dos conflitos sociais. 2 ed. São Paulo: Ed.34, 2009.

MATTOS, P.C. Reconhecimento: entre a justiça e a identidade. Lua Nova. Revista de Cultura e Politica. São Paulo, v. 63, n.1, p. 143-161, 2004.

MEAD, G.H. Selected writings. Indianópolis: Bobbs-Merrill, 1964.

MIRANDA, L.; ONOCKO CAMPOS, R. Análise das equipes de referência em saúde mental: uma perspectiva de gestão da clínica. Cadernos de Saúde Pública. Rio de Janeiro,v. 26, n.6, p.1153-1162, 2010.

NOBRE, M. Apresentação. In: Honneth, A. Luta por reconhecimento: a gramática moral dos conflitos sociais. 2 Ed. São Paulo: Ed. 34, 2009. p.1-19.

ONOCKO CAMPOS, R. O encontro trabalhador-usuário na atenção à saúde. Uma contribuição da narrativa psicanalítica ao tema do sujeito na saúde coletiva. Ciência \& Saúde Coletiva. Rio de Janeiro, v. 10, n.3, p. 573-583, 2005.

PEDUZZI, M. Equipe multiprofissional de saúde: conceito e tipologia. Revista de Saúde Pública. v.35, n.1, p.103-9, 2001.

. Trabalho em equipe de saúde no horizonte normativo da integralidade, do cuidado e da democratização das relações de trabalho. In: PINHEIRO, R.; BARROS, M.E.B. (Org.). Trabalho em equipe sob o eixo da integralidade: valores, saberes e práticas. Rio de Janeiro: Cepesc, 2007.p. 161-177.

PEREIRA, R.S.A. O trabalho multiprofissional na Estratégia da Saúde da Família: estudo sobre modalidades de equipe. 2011. 134 p. Dissertação (Mestrado em Saúde Coletiva) - Escola Nacional de Saúde Pública Sergio Arouca, Fundação Oswaldo Cruz, Rio de Janeiro, 2011.

RIVERA, F.J.U. Cultura e liderança comunicativa. In: . Análise estratégica em saúde e gestão pela escuta. Rio de Janeiro: Fiocruz, 2003. p.185-218. 
SAAVEDRA, G.A. A teoria crítica de Axel Honneth. In: SOUZA, J.; MATTOS, P. (Org). Teoria crítica no século XXI. São Paulo: Anablume, 2007. p. 95-112.

TEIXEIRA, R. O acolhimento no serviço de saúde entendido como uma rede de conversaçôes. In: MATTOS, R.A.; PINHEIRO, R. (Org.). Construção da Integralidade: cotidiano, saberes e práticas em saúde. Rio de Janeiro: Cepesc, 2003. p.89-111.

VASCONCELLOS, M.F.F.; MORSCHEL, A. O apoio institucional e a produção de redes: o desassossego dos mapas vigentes na saúde coletiva. Interface. Botucatu, v.13, n.1, p.729- 38, 2009.

WERLE, D.L. Reconhecimento e emancipação. A teoria crítica de Axel Honneth. Mente, cérebro \& filosofia. São Paulo, p. 1- 2, 2008.

WINNICOTT D.W. O brincar e a realidade. Rio de Janeiro: Imago, 1975.

. Desenvolvimento emocional. Características da primeira infância. In:

Natureza Humana. Rio de Janeiro: Imago, 1990. p. 87-99.

\section{Nota}

${ }^{1}$ Todos os autores participaram igualmente da elaboração do artigo. 
Interdisciplinary health care teamwork as a space of recognition: contributions of Axel Honneth's theory

This theoretical study aims to correlate the discussion about interdisciplinary teamwork in public health institutions with the key concepts of contemporary philosopher Axel Honneth with regards to what he called the Struggle for Recognition. We start by revising the notion of subject in Honneth's theory, especially based on his dialogue with Donald Winnicott's psychoanalysis. We highlight that this subject is eminently social; its constitution depends on the recognition of others regarding its otherness and the legitimacy of its belonging to a social group. Next, we show that this recognition occurs through a process of struggle, which is essential for developing the capacity to love and to relate to others. We then argue that the work in interdisciplinary teams can be configured as a potent space for the recognition of professionals, as discussed by Honneth. Teams may thus facilitate the development of creative work and innovations in the organization of care provided to patients.

> Key words: patient care team; professional-patient relations; interdisciplinarity; intersubjectivity; Axel Honneth. 